\title{
Schizencéphaly, a Rare Case in Ebolowa Regional Hospital, South
} \section{Cameroon}

Keywords: Schizencephaly; Mutation; Crack; Development delay

Schizencephaly, also called split brain disease, is a medical condition due to a crack in the cerebral tissue. The disease is rare. It is due to the poor anatomical development of the brain during the first 7 months of pregnancy. The real etiology is unknowned, probably due to infection, stroke, mutation of genes EMX2, SIX3, SHH, COL4A1, further medications and young maternal age.

The symptoms are seizures, developmental delay, intellectual disability, partial or complete paralysis, hypotonia, hydrocephaly, microcephaly but in this medical case the symptoms are few. But probably the early diagnosis can be the prevention of complications like hydrocephaly. The prognosis is uncertain and the treatment is not available.

The patient is a female baby of 18 months, Cameroonian living in Ebolowa. Both parents are students. The mother is 20 years old, and the father 24 years old. The previous consultation was one month ago.

The mother was complaining of the difficulty of the child to move, to sit down, and to hold the head since the age of 7 months. She has been taking further medication, kinesitherapy, calcium, Uteplex, and indigenous treatment. It is the second pregnancy Torch unknown prenatal consultation, prenatal consultation 4. No information about echography during pregnancy. The child was born normally no resuscitation lower way delivery. No more information. The child has not been hospitalized. No surgery, no allergy, gastrointestinal infections some time. She has been breastfeeding for 6 months, no vitamin $\mathrm{D}$. He sleeps under a bed net. He has been taking vaccines till 9 months. She has been de wormed. The child is not talking. She is not sitting. Denver scale poor social contact, she is using spoon. Poor motricity adaptation she is not drawing, she cannot associate 2 words, and she is not playing. The first child has 3 years old he is in good shape. The parents are in good shape actual weight $7 \mathrm{~kg}$ height $74 \mathrm{~cm}, \mathrm{~W} / \mathrm{H}-3 \mathrm{Z}$ score cranial perimeter $46,5 \mathrm{~cm}$.

Physical exam the child is conscious Blantyre 5/5, well colored, nystagmus, strabismus, lung vesicular murmur, normal heart

\section{Journal of \\ Pediatrics \& Child Care}

Nana Pamela*, Dongmo Nanfack Christelle, Abena
Abena Jean-Jacques Parfait, Kemeni Ulrich Thibaut, Mbiah Cyriaque and Jiatsa Reine

Paediatric Unit, Ebolowa Regional Hospital, Ebolowa, Cameroon *Address for Correspondence:

Nana Pamela, Paediatric Unit, Ebolowa Regional Hospital, Ebolowa, Cameroon, Tel : 23795179021; E-mail: nanouchkina@yahoo.fr

Submission: 24 January, 2017

Accepted: 21 February, 2017

Published: 27 February, 2017

Copyright: ๑ 2017 Pamela N, et al. This is an open access article distributed under the Creative Commons Attribution License, which permits unrestricted use, distribution, and reproduction in any medium, provided the original work is properly cited.

beating, normal abdominal wall, no organomegaly, stool and urine are normal.

Osteotendinous reflexes are quick on the right lower limb with high muscle tone, spasticity, babinsky sign is negative. The first diagnosis and associate diagnosis pyramidal syndrome, paralysis of VI occulomotor nerve, cerebral motricity deficiency, psychomotor developmental delay, severe malnutrition.

The statement was IGM toxoplasmosis, HIV test, and cerebral Tomodensitometry.

IGM toxoplasmosis was not available.

HIV test is negative.

Cerebral Tomodensitometry showed: broad crack of the right lateral ventricle with arachnoids dilatation. The conclusion of the radiologist was cystic schizencephaly or type II.

The prognosis is uncertain the child has been referred to the neurologist in Yaoundé after the nutritional care, kinesitherapy, vit $\mathrm{D}$ and Gamalate B6 treatment. The child will probably have handicap and disabilities. The $\mathrm{G}$ treatment is not available in our country if it is available will it be useful for the child? We are open to further information about the treatment and medical care.

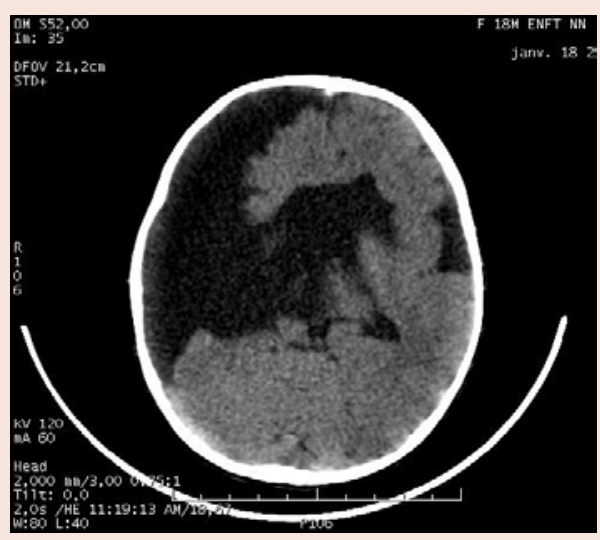

